\title{
High-Temperature Protective Coatings Produced by EB-PVD
}

\author{
B.A. Movchan and Yakovchuk K. Yu* \\ International Center for Electron-Beam Technologies of E.O. Paton Electric Welding Institute of National Academy of Science of \\ Ukraine
}

\begin{abstract}
The paper presents some new technological sequences of electron beam evaporation and deposition of high-temperature metal-ceramic coatings.

The main attention is given to two-layer Me-Cr-Al- $\mathrm{Y} / \mathrm{ZrO}_{2}-\mathrm{Y}_{2} \mathrm{O}_{3}$ coatings with transition layers of the total thickness of up to $0.2 \mathrm{~mm}$.

Chemical composition and structures of the main layers (metal, ceramics) and substrate/metal and metal/ceramics transition layers, as well as the respective physico-mechanical properties are considered.
\end{abstract}

A method of deposition of these coatings in one technological cycle of evaporation and condensation with application of evaporation composite ingot is proposed.

Examples of coating "design" and respective equipment for practical application in gas turbine construction are given.
Received on 27-05-2014

Accepted on 27-06-2014

Published on $30-10-2014$

Keywords: Electron-beam evaporation and deposition (EB-PVD), high-temperature coating, multilayered thermalbarrier coating, crucibleevaporator, gas turbine blades.

\section{INTRODUCTION}

Creation of high-temperature protective coatings is a cardinal and economically sound solution of the problem of combining high structural strength of materials with their ability to withstand chemical destruction at high temperatures. At present various methods of coating deposition are applied: electrochemical deposition from water solutions and salt melts, chemical deposition from the gas phase, diffusion saturation of the surface, flame, plasma and detonation spraying, and vacuum deposition methods.

Vacuum methods of coating deposition based on physical processes of evaporation, atomization and condensation, compare favourably with other methods by their precision and practically unlimited capabilities of controlling coating structure and properties.

The vapour phase has no limitation on mutual solubility of components. Simultaneous evaporation of several metals, alloys or refractory compounds, mixing of their vapour (atomic-molecular) flows and subsequent condensation, enable producing various combinations (compositions) of

"International Center for Electron-Beam Technologies of E.O. Paton Electric Welding Institute of National Academy of Science of Ukraine, 03150, Kiev, Gorky str., 68, e, Ukraine; Tel: +38 044-289-2176; Fax: +38 044 287-3166; E-mail: yakovchuk@paton-icebt.kiev.ua metallic and nonmetallic materials, practically unachievable by other methods.

Evaporation and condensation allows producing metal, ceramic, metal-ceramic coatings: single-phase, multiphase, dispersion-strengthened, microporous, microlayered with micro- and nanosized structure.

Heating and high-rate evaporation of initial inorganic substances is performed by electron beam (accelerated flow of electrons) generated by electron beam gun.

Electron beam is one of the most effective heat sources. The main fraction of kinetic energy of electrons at collision with a heated surface turns into thermal energy in a thin surface layer 1-2 mm thick. Therefore, at electron beam heating the heat source is located in the heated body proper, and ensures maximum complete transformation of electric energy into thermal energy with a high level of adjustment of heating and evaporation processes.

So far, extensive technological experience has been gained of application of inorganic coatings produced by electron beam evaporation and physical deposition of the vapour phase in vacuum - EB-PVD method [1-5].

Some results of investigation and development of hightemperature composite protective coatings are given below. 
EVAPORATORS, MATERIALS AND TECHNOLOGICAL VARIANTS OF EVAPORATION

An accelerated electron flow is generated by electron beam guns, which together with crucibles with evaporation materials, are the main elements of evaporators at deposition of high-temperature coatings by EB-PVD method [4-6].

Modern electron guns of 50 to $100 \mathrm{~kW}$ power enable evaporation of metallic and non-metallic materials at high enough rates, approximately up to $10^{-2} \mathrm{~g} \cdot \mathrm{cm}^{-2} \cdot \mathrm{s}^{-1}$. The most widely used are evaporators, consisting of a copper watercooled cylindrical crucible, which accommodate the evaporation material in the form of an ingot (cast or compacted) 25 to $70 \mathrm{~mm}$ in diameter, Figure 1.

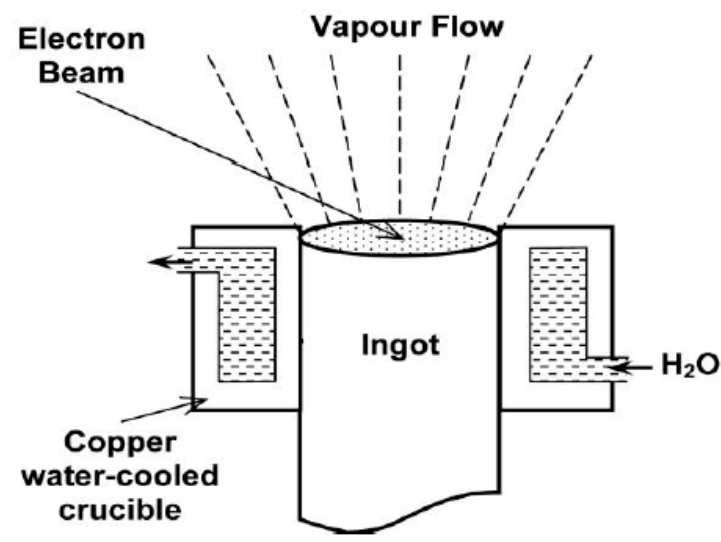

Figure 1: Schematic of electron beam evaporation of an ingot from a cylindrical water-cooled copper crucible.

Ingot surface, molten and overheated by electron beam, forms a liquid pool, the surface of which intensively evaporates. Inner cooling of copper crucibles by flowing water prevents interaction with the liquid pool, even in the case of evaporation of refractory metals and compounds that is why such evaporators are long-lasting.

The level of liquid pool surface, from which evaporation proceeds, is kept constant in most of the cases, using the mechanism of vertical displacement of the ingot. At evaporation in the vacuum of $10^{-4}-10^{-6}$ Torr, the spatial density of the vapour flow above the evaporator follows the cosinusoidal law of distribution, according to which the maximum density is observed in the direction of the normal to the evaporation surface (angle $\alpha=0$ ).

Using $70 \mathrm{~mm}$ diameter ingots for evaporation, it is possible to achieve the following maximum evaporation rates: $3 \mathrm{~kg} / \mathrm{h}$ for $\mathrm{Fe}, 1.5 \mathrm{~kg} / \mathrm{h}$ for Ni alloys, $1.0 \mathrm{~kg} / \mathrm{h}$ for graphite, $0.8 \mathrm{~kg} / \mathrm{h}$ for $\mathrm{ZrO}_{2}$. The rate of vapour flow condensation on a flat stationary substrate located above the liquid pool surface at $300 \mathrm{~mm}$ distance, can be up to $30-50 \mu \mathrm{m} / \mathrm{min}$ for metals and alloys and $15-20 \mu \mathrm{m} / \mathrm{min}$ for ceramics (oxides, carbides, borides).

Similar to alloys, pure metals are evaporated as individual atoms. For most of the alloys, however, the composition of the vapour phase above the liquid alloy is not equivalent to the average alloy composition. Alloy fractionation occurs, namely condensate layers adjacent to the condensation surface, contain maximum amounts of volatile components. Condensates of multicomponent metallic materials of a composition homogeneous across their thickness are produced, using various evaporation techniques, including evaporation of individual alloy components from independent sources.

Evaporation of compounds (oxides, carbides, borides, etc.) is, as a rule, accompanied by a change of the kind of the initial molecules. Many of the refractory compounds are characterized by dissociation of the initial molecules with formation of gaseous products. Results of analysis of thermal dissociation of compounds are generalized in $[2,5]$.

Producing condensates by direct evaporation from one source without any change of the initial composition of the compounds, is possible only under the condition that the dissociation products have practically the same volatility, i.e. a harmonized "congruent" evaporation of the compounds is required. Refractory oxides $\left(\mathrm{Al}_{2} \mathrm{O}_{3}, \mathrm{Y}_{2} \mathrm{O}_{3}, \mathrm{ZrO}_{2}, \mathrm{MgO}\right)$, carbides ( $\mathrm{TiC}, \mathrm{ZrC}, \mathrm{NbC}$ ), borides $\left(\mathrm{TiB}_{2}, \mathrm{ZrB}_{2}\right)$ can be evaporated from water-cooled copper crucibles, using electron beam heating practically without any change in the composition. A number of compounds, for instance WC, TiN, AIN, ZrN cannot be deposited by direct evaporation, as they decompose at heating, forming products with markedly different volatility.

Such compounds can be produced in the form of condensates by component evaporation from two independent sources or using the so-called reactive evaporation with bleeding the appropriate gas into the working chamber and vapour flow ionisation [5].

High-temperature oxidation-resistant metal coatings usually are based on nickel or cobalt aluminides. Basic system of high-temperature single-layer coatings, which became widely accepted, are alloys of Me-Cr-Al-Y type (where Ni, Co or their combinations are used as $\mathrm{Me}$ ). Aluminium and chromium are elements ensuring formation of $\alpha-\mathrm{Al}_{2} \mathrm{O}_{3}$ based oxide layer on coating surface at elevated temperature, and yttrium (as well as $\mathrm{Ce}, \mathrm{La}, \mathrm{Hf}, \mathrm{Si}$ ) is a microalloying element, improving adhesion of this layer. Application of such coatings on the surface of gas turbine blades by electron beam evaporation in vacuum allows 3-5 times extension of their service life [7].

Further improvement of protective metal coatings was achieved by additional deposition of an outer ceramic layer.

Modern protective coatings are a multilayered structure: inner metal oxidation-resistant layer based on Me-Cr-Al-Y alloys or NiAl, CoAl, PtAl intermetallics; outer low heat-conducting ceramic layer, as a rule, based on partially stabilized zirconium dioxide (YSZ) and aluminium oxide interlayer, connecting the outer and inner layers. It is universally recognized that thermal-barrier coatings, in which outer 
ceramic layer is produced by EB-PVD method, have the longest operating life [3, 8-10].

By now technological variants of producing high-temperature single-layer metal (Me-Cr-Al-Y type) and $\mathrm{ZrO}_{2}-8$ wt. $\% \mathrm{Y}_{2} \mathrm{O}_{3}$ (8YSZ) ceramic coatings by electron beam evaporation of ingots of the respective chemical composition from a cylindrical evaporator have been optimized and are widely applied, Figure 1 [4,5,7,8,11-15].

In order to increase the rate of evaporation (condensation) of alloys of Me-Cr-Al-Y type, as well as ensure guaranteed transfer of chemical elements with a low vapour pressure for instance yttrium, from the alloy into the condensate, a method of high-rate evaporation, using "hot" intermediate pool from refractory metals, was proposed [16]. The essence of the method consists in initial formation of an intermediate pool of about $10-15 \mathrm{~mm}$ depth on the surface of evaporation ingot from Me-Cr-Al-Y type alloy, by adding up to $80 \mathrm{wt} \%$ of refractory metal $(\mathrm{W}, \mathrm{Nb}$ or $\mathrm{Ta})$. This pool composition remains unchanged during the entire time of ingot evaporation. Application of this technology allows 2-3 times increasing evaporation rate of Me-Cr-Al-Y type alloys, as well as more accurately transferring $\mathrm{Y}$ from evaporation ingot into the coating. Moreover, at evaporation with application of "hot" intermediate pool the number of defects (intercolumnar leaders and microdrops) in the structure of deposited metal layer is abruptly reduced.

The traditional technological cycle of deposition of two-layer thermal barrier coatings consists of several stages and operations, including deposition of metal oxidation- and corrosion-resistant layer (by diffusion saturation, electrochemical deposition, plasma spraying or by EB-PVD method), subsequent intermediate variants of heat treatment, compacting and cleaning of this layer surface and final deposition of a ceramic layer [4, 5, 7-10]. Multistage nature of the process cycle and diverse equipment applied in this case, make it difficult to ensure reliable repeatability and quality, while simultaneously improving the coating cost.

An EB-PVD method was proposed to produce multilayered high-temperature coatings of metal-ceramic type, including

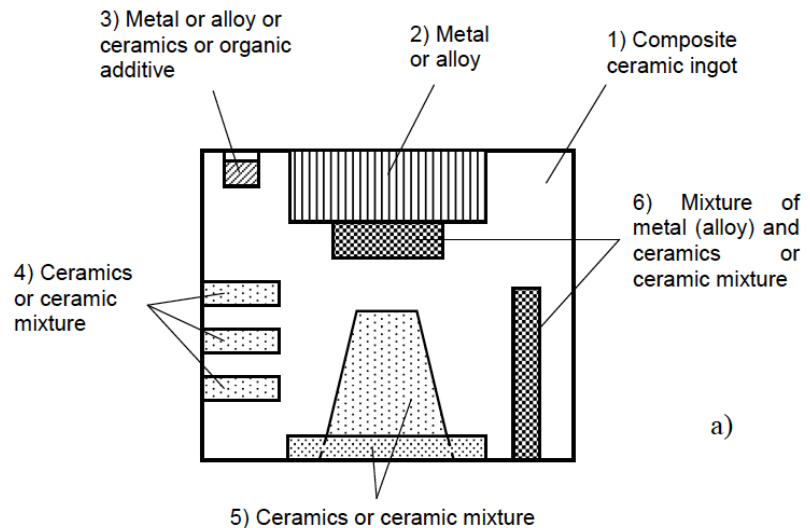

graded coatings, in one technological cycle from one evaporator [17] with application of a composite ceramic ingot.

Figure $\mathbf{2 a}$ and $\mathbf{2} \mathbf{b}$, respectively, show the design schematic and overall view of a composite ingot. Composite ingot 1 , preferably of a cylindrical shape, consists of a ceramic base and individual fragments (inserts 2-6) of metallic and nonmetallic materials of the required shape and dimensions, selected and arranged in the ingot volume so that a graded multilayered coating of the specified composition and structure would form on the substrate at continuous evaporation and subsequent condensation of the vapour phase.

The composite ingot incorporates the program of evaporation and deposition of a graded multilayered coating, embodied in the shape, dimensions and quantity of the respective inserts (fragments), their composition and spatial arrangement in the bulk of the basic ingot.

Technique of composite ingot evaporation is traditional: the ingot is placed into copper water-cooled crucible and its upper edge is heated smoothly and gradually melted, and then evaporation is begun (up to its complete evaporation). Surface of ingot liquid pool is kept on a constant level due to vertical feeding of the ingot on a rod.

Ingot ceramic base predetermines the graded coating purpose. For instance, for thermal barrier coatings this is $\mathrm{ZrO}_{2}$ with additives of stabilizers and other oxide systems of low heat conductivity. For heat- and erosion-resistant coatings the ceramic base of the ingot from $\mathrm{Al}_{2} \mathrm{O}_{3}$, and for wear-resistant coatings - from $\mathrm{Al}_{2} \mathrm{O}_{3}, \mathrm{TiC}$ or $\mathrm{TiB}_{2}$, are required.

Inserts 2 and 3 located in the upper part of the composite ingot, have the shape of tablets or rods, and being the first to evaporate, are designed to produce transition layers of the required composition and structure on the substrate. They can be manufactured from organic compounds, metals, alloys or ceramics with melting temperature lower and vapour pressure higher than those of ingot base, for instance,

Figure 2: Schematic of composite ingot design (a) and overall view (b). 
anthracene $\mathrm{C}_{14} \mathrm{H}_{10}, \mathrm{Al}, \mathrm{Cr}, \mathrm{NiAl},(\mathrm{NiCr}) \mathrm{Al}, \mathrm{Pt}, \mathrm{PtAl}$, (NiPt)Al, etc.

Inserts 4 and 6 located in the medium and lower parts of the composite ingot, are manufactured, predominantly from ceramics or ceramic mixtures with melting temperature and vapour pressure close to those of ingot base, for instance, $\mathrm{Al}_{2} \mathrm{O}_{3}, \mathrm{CeO}_{2}, \mathrm{HfO}_{2}$, etc. Evaporating and condensing simultaneously with ingot base ceramics, they form the composition, structure and properties of the ceramic layer (or layers) of the graded coating, primarily, microporous structure.

Formation of graded coating upper layer of complex multiphase ceramics is achieved by placing in the ingot lower part contacting the cooled surface of the rod, an insert-tablet 5 from non-metallic materials with a wide range of melting temperature and vapour pressure. The tablet is the last to evaporate and completes graded coating formation, and its composition and condensation conditions determine the density and hardness of the coating upper layer.

Technique of evaporation of composite ceramic ingot practically does not differ from evaporation of traditional ingots: initially smooth heating of the upper edge of the ingot with gradual transition to its evaporation, which is continued up to complete evaporation of the ingot. Liquid pool surface is maintained on a constant level by vertical feed of the ingot, using a water-cooled shaft.

\section{STRUCTURE OF HIGH-TEMPERATURE COATINGS AND METHODS TO CONTROL IT}

Investigations of the structure and properties of coatings were made on samples, produced by evaporation of initial materials in the form of metal and ceramic ingots of $68.5 \mathrm{~mm}$ diameter in electron beam units of UE-204 and UE-207 type [18], using direct electron beam heating of samples [3, 19]. Flat samples from low-carbon steel $4 \mathrm{~mm}$ thick (at deposition on a stationary substrate), as well as button-samples of 25.4 $\mathrm{mm}$ diameter and $4 \mathrm{~mm}$ thickness, made from various nickelbase superalloys (at deposition on a rotating substrate) were used. Button-samples were placed into a hexagonal fixture, fastened on the horizontal shaft, rotating at the speed of 25 $\mathrm{rpm}$, and coating was deposited on one side of the sample, Figure 3. Beam current at evaporation of alloys of MeCrAlY type was equal to 1.7-1.8 A (vacuum of about $1 \times 10^{-4} \mathrm{Torr}$ ), beam current at evaporation of $8 \mathrm{YSZ}$ ingots was equal to 1.31.4 A (vacuum of about $3 \times 10^{-4} \mathrm{Torr}^{-4}$ ), accelerating voltage is $20 \mathrm{kV}$. Distance from the evaporation ingot surface to the samples was equal to $300 \mathrm{~mm}$, with samples positioned above the ingot being evaporated.

Deposition of outer 8YSZ ceramic layer about $170 \mu \mathrm{m}$ thick to study its thermal conductivity, was performed on buttonsamples of $12.7 \mathrm{~mm}$ diameter (FeCrAlY alloy $0.48 \mathrm{~mm}$ thick and $1.02 \mathrm{~mm}$ thick sapphire were used as sample material), also fastened in the rotating fixture, Figure 3. Investigations of ceramic layer heat conductivity were conducted by laser flash-procedure and in the equipment, described in work [20].

Microstructure of the produced coatings, as well as thickness of individual layers, was studied in PolivarMet optical microscope and CamScan 4D scanning electron microscope. Deposited layer composition was determined with EDX attachment INCA-200 to scanning electron microscope. Microhardness of outer ceramic layer was measured in Micro-Duromat $4000 \mathrm{E}$ attachment by standard diamond Vickers indenter at $0.49 \mathrm{~N}(50 \mathrm{~g})$ load with fixed loading rate and time of soaking under load.

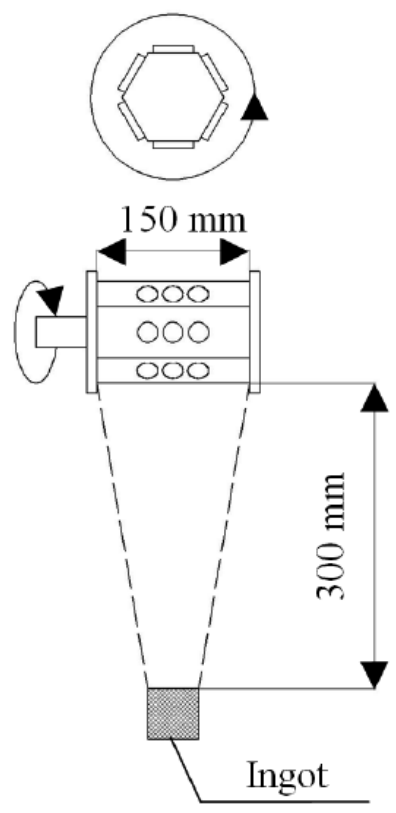

a)

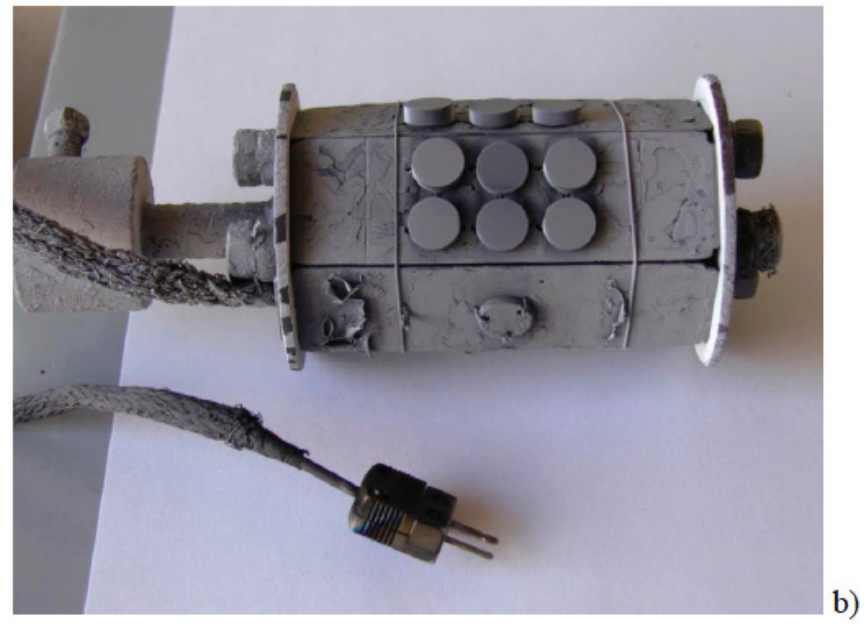

Figure 3: Schematic (a) and overal view (b) of flat button samples arrangement in the fixture at coating deposition on a rotating substrate. 
Investigations of furnace cyclic life of thermal barrier coatings deposited on samples from various superalloys of $25.4 \mathrm{~mm}$ diameter and $4 \mathrm{~mm}$ thickness, were conducted in Automatic Rapid Temperature Furnace CM (USA) by testing in the following mode: heating up to $1150^{\circ} \mathrm{C}$ (or $1093^{\circ} \mathrm{C}$ ) for $7 \mathrm{~min}$, sample soaking in the furnace at this temperature for $45 \mathrm{~min}$, sample cooling down to temperature of $40^{\circ} \mathrm{C}$ was performed by blowing of their surface by an air flow using a fan during 8 min. Testing was stopped after coating failure, which was taken to be $8 Y S Z$ layer spallation from $20 \%$ of sample surface area.

Substrate temperature, $T_{s}$, is known to be the main parameter controlling the condensed layer structure, i.e. temperature of the surface, on which the vapour atomicmolecular flow of evaporation material is deposited. Atoms (molecules) of the vapour flow having a certain kinetic energy, during interaction (collision) with the condensation surface, go into adsorbed state and exchange energy with surface atoms, jumping over this surface. Condensation surface temperature predetermines the level of thermal activation of an adsorbed atom, number of jumps, probability of collision and interaction with other adsorbed atoms and formation of the respective atomic configuration.

It is found that at direct electron beam evaporation of pure metals and refractory compounds of the type of oxides, carbides, borides and subsequent deposition of the vapour flow on the substrate heated with a gradient, three characteristic structural zones form, depending on substrate temperature [21, 22]. Figure 4 gives the schematic of the structural zones, depending on the homological temperature $T_{s} / T_{m}\left(T_{m}\right.$ in the melting temperature in $\left.K\right)$.

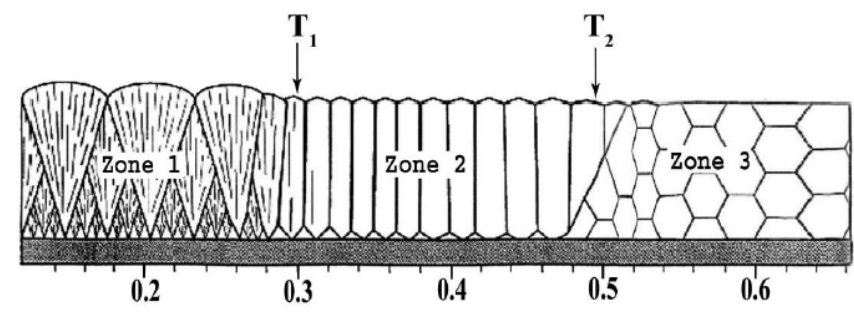

Homologous Temperature $T_{s} / T_{m}$

Figure 4: Schematic of condensate structure depending on substrate temperature $T_{s}$.

For instance, for pure nickel condensates the average values of boundary temperatures are equal to $\mathrm{T}_{1}=270^{\circ} \mathrm{C} ; \mathrm{T}_{2}=$ $450^{\circ} \mathrm{C}$.

Evaluation of activation energy of thermally activated processes in the above zones enabled suggesting the main mechanisms controlling structure formation in each of them. A limited transition (jump) of the atoms from one neighbouring equilibrium position to another on the condensation surface in the first zone; surface diffusion in the second zone and bulk diffusion in the third zone [21].
Accordingly, in the low-temperature zone $\left(T_{s}<T_{1}\right)$ the condensates have an porous structure with tapered crystallites with rough surfaces are formed owing to low adatom mobility (slow surface diffusion). In the second zone $\left(T_{1}-T_{2}\right)$ the condensates are characterized by a columnar structure with a predominantly crystallographic orientation. Width of the columnar crystallites increases with temperature in $T_{1}-T_{2}$ range from fractions of a micrometer up to several micrometers.

Figure 5 shows the dependence of the change of structure and microhardness of $8 Y S Z$ condensate $70 \mu \mathrm{m}$ thick on substrate temperature $T_{\mathrm{s}}$. The condensate was produced at deposition at $4 \mu \mathrm{m} / \mathrm{min}$ rate on a flat stationary substrate from low-carbon steel.

At 8YSZ deposition on a stationary substrate in the temperature range of $270-540^{\circ} \mathrm{C}$ the condensed layer has a porous highly defective structure with relatively low microhardness. At further increase of condensation temperature (i.e. in the $2^{\text {nd }}$ structural zone above $T_{1}$ temperature) the deposited layer has a clearly pronounced columnar microstructure, its microhardness increasing with temperature due to formation of a denser structure (intercrystalline porosity decreases). Starting with substrate temperature of $940^{\circ} \mathrm{C}$ and higher microhardness increase is slowed down, and a practically pore-free structure of the ceramic layer forms.

Angle of incidence of the vapour flow (flying atom) on the condensation surface is another process parameter, determining condensate structure, particularly in columnar crystallite zone.

Therefore, the main investigations were performed at coating deposition on rotating substrates, i.e. on button-samples of $25.4 \mathrm{~mm}$ diameter and $4 \mathrm{~mm}$ thickness, made from various nickel-base superalloys and fastened in a rotating fixture during coating deposition on them, in keeping with the schematic in Figure 3.

Figure 6 gives examples of microstructure of condensed $8 Y S Z$ layer produced at its deposition at different temperature on the surface of samples from nickel superalloy with earlier deposited NiCoCrAlY layer 90-100 $\mu \mathrm{m}$ thick, samples rotating in the vapour flow of evaporation material at the speed of 25 rpms.

In addition to influence of temperature (i.e. diffusion mobility of atoms on condensation surface) the effect of shadowing at substrate rotation (change of the angle of vapour flow incidence) also influences the forming structure of the condensed $8 \mathrm{YSZ}$ layer. As a result, at substrate temperature of $600^{\circ} \mathrm{C}$ a highly porous ceramic layer with a columnar microstructure forms, intercrystalline porosity being a special feature of this layer, as each individual columnar crystallite has inner dendritic structure, Figure $\mathbf{6 a}$. 

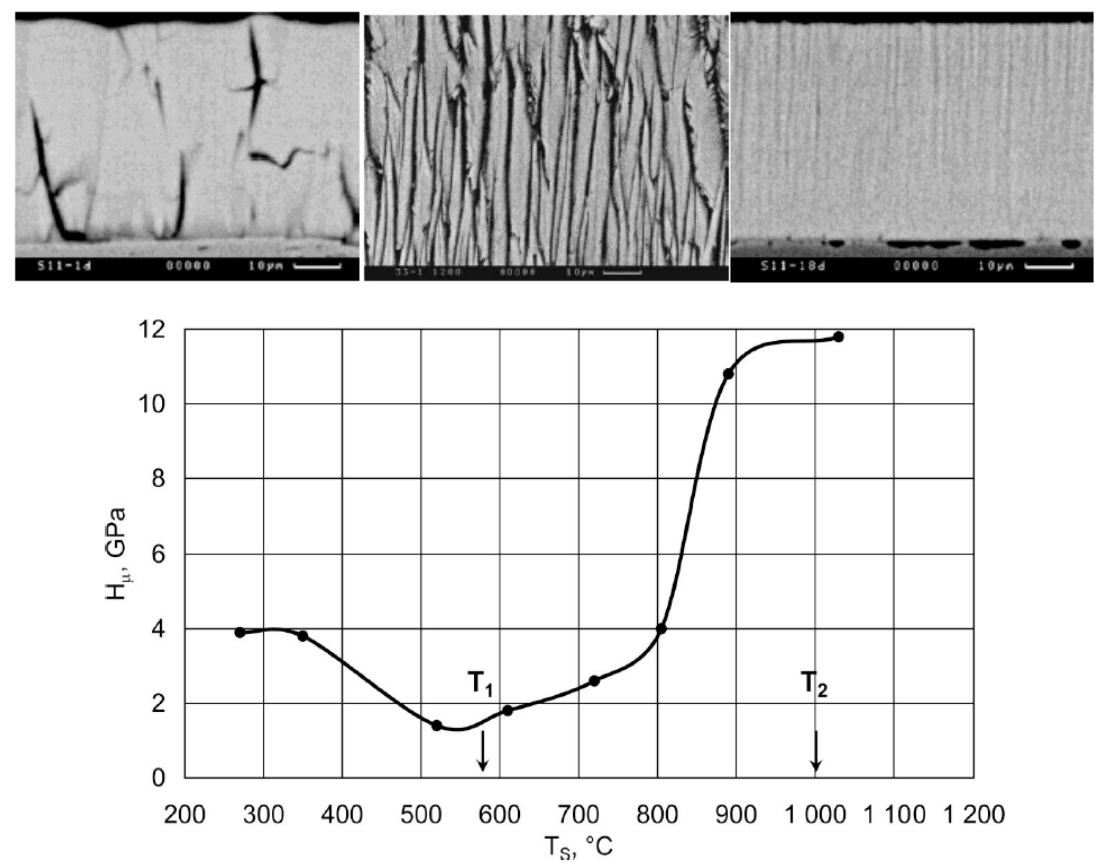

Figure 5: Change of microhardness and microstructure of condensed $\mathrm{ZrO}_{2}-8 \mathrm{wt} . \% \mathrm{Y}_{2} \mathrm{O}_{3}$ layer, depending on substrate temperature.

With substrate temperature rise, intercrystalline porosity decreases, growing individual columnar crystallites become denser, and their dendritic structure degenerates, Figure $\mathbf{6 c}$.

Width of an isolated columnar crystallite, oriented normal to condensation surface, becomes greater with increase of condensation temperature and is equal to about $2 \mu \mathrm{m}$ at $600^{\circ}$, and about $5-6 \mu \mathrm{m}$ at $850^{\circ}$ and $1000^{\circ} \mathrm{C}$. Width of intercrystalline pores in $8 Y S Z$ layer also increases from $1 \mu \mathrm{m}$ to 3-4 $\mu \mathrm{m}$ at increase of condensation temperature from $600^{\circ}$ up to $1000^{\circ} \mathrm{C}$. A characteristic feature of $8 \mathrm{YSZ}$ crystallites deposited at $600^{\circ} \mathrm{C}$ is developed intercrystalline porosity, which degenerates with increase of condensation temperature into isolated pores, oriented along the condensation axis.
One of the main characteristics of outer ceramic layer of thermal-barrier coatings is its thermal conductivity that is largely determined by the level of porosity, both intercrystalline and intracrystalline [7-9]. Figure 7 gives the results of investigation of thermal conductivity of a ceramic layer about $170 \mu \mathrm{m}$ thick deposited at different substrate temperature.

Data given in Figure 7 on influence of substrate temperature on thermal conductivity of the condensed 8YSZ layer (lines 1 , 2 and 4 ) are indicative of the fact that at condensation temperature of $850^{\circ} \mathrm{C}$ the level of thermal conductivity in the entire range of measurement temperature was equal to $1.3-$ $1.4 \mathrm{~W} / \mathrm{m} \cdot \mathrm{K}$. It can be noted that the obtained values of thermal conductivity are somewhat lower than thermal conductivity data available in literature for $8 \mathrm{YSZ}$ layer

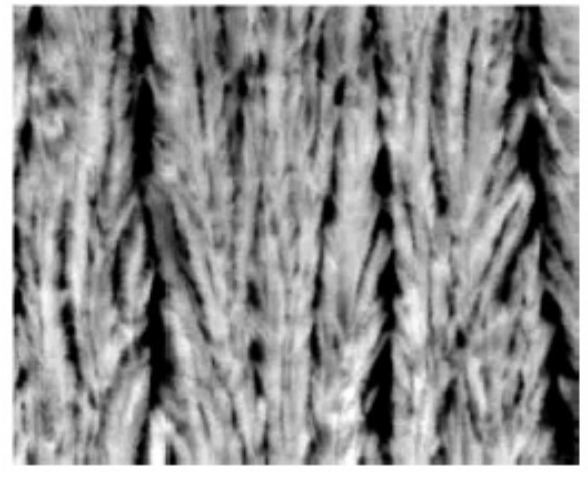

$\mathrm{x} 2500$

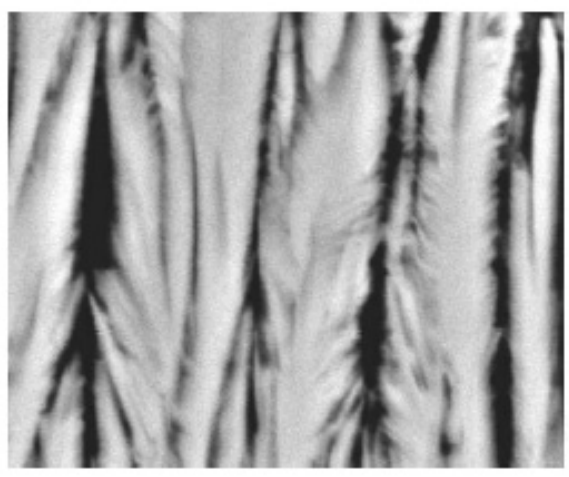

$\mathrm{x} 2500$

b)

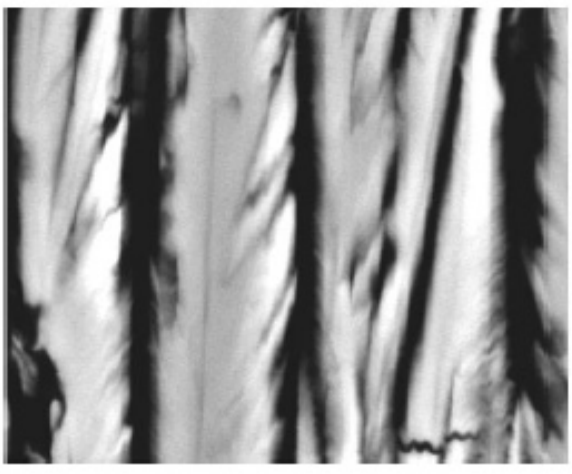

$\mathrm{x} 2500$

c)

Figure 6: As-deposited cross-sectional structure of $8 \mathrm{YSZ}$ ceramic layer. Condensation temperature $\mathrm{Tc}=600^{\circ}(\mathbf{a}), 850^{\circ}(\mathbf{b})$ and $1000^{\circ} \mathrm{C}(\mathbf{c})$. 
$[8,13,20,23]$, which were obtained at substrate temperature of $900-1000^{\circ} \mathrm{C}$. The main factor influencing thermal conductivity of $8 \mathrm{YSZ}$ layer, is its porosity, and in our opinion intercrystalline porosity plays the determinant role here. This is confirmed by the fact that the layer deposited at $600^{\circ} \mathrm{C}$ (line 4 ), has the lowest heat conductivity. It is obvious that the characteristic intercrystalline (interdendritic) porosity makes the determinant contribution to its relatively low heat conductivity $(0.9 \mathrm{~W} / \mathrm{m} \cdot \mathrm{K})$.

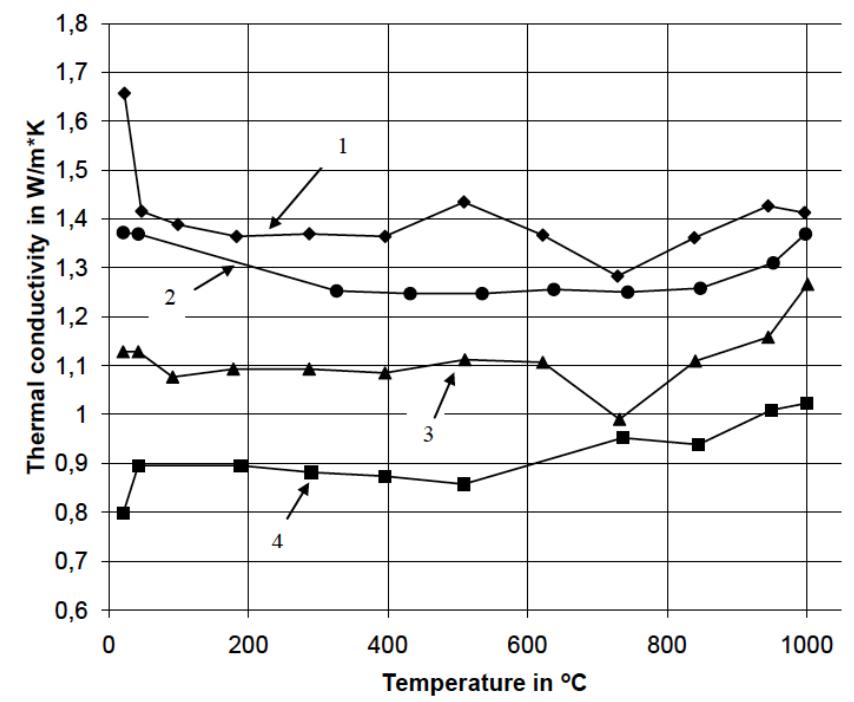

Figure 7: Dependence of thermal conductivity of outer ceramic layer on its composition and deposition conditions:

1 - 8YSZ on FeCrAIY substrate, deposition temperature $850^{\circ} \mathrm{C}$;

2 - 8YSZ on sapphire substrate, deposition temperature $850^{\circ} \mathrm{C}$;

$3-8 \mathrm{YSZ}+\mathrm{Gd}_{2} \mathrm{O}_{3}$ on FeCrAlY substrate, deposition temperature 850 ${ }^{\circ} \mathrm{C}$;

$4-8 Y S Z$ on sapphire substrate, deposition temperature $600^{\circ} \mathrm{C}$.

Structure of outer ceramic layer formed at condensation from the vapour phase, in addition to substrate temperature, is largely determined also by such process parameters, as angle of incidence of the vapour flow, pressure in the working chamber, coating deposition rate $[13,24-26]$. It is shown that with increase of angle of incidence of vapour flow on condensation surface, microhardness and brittle fracture resistance of a ceramic coating decrease, and porosity is increased.

Known are technological sequences of application of the change of angle of incidence of 8YSZ vapour flow deposited on the substrate (due to application of special fixtures to change the orientation and movement of the substrate in the vapour flow), or use of alternate deposition from 2 evaporators $[27,28]$ to form the so-called zigzag microstructure of the ceramic layer, having a lower heat conductivity [29].

Note also the possibility of introducing additional components into evaporation material vapour flow, changing both the condensed layer structure and its composition. Special attention should be given to additives to the vapor phase at evaporation of $\mathrm{ZrO}_{2}$ and other oxides to obtain a microporous thermally-stable structure of ceramic layer with a low thermal conductivity [30]. One should separately note oxidesstabilizers (primarily, rare-earth oxides), which are added to zirconium dioxide to lower its heat conductivity [8, 31].

All the additives, by the degree of their chemical interaction with vapour and solid phase of the main component at the stage of condensate formation and subsequent heat treatment operations, can be divided into three groups, with a certain degree of conditionality.

1. Inert additives, practically not interacting with the main component and staying in the condensate volume in the form of second phase particle.

2. Inert additives, practically not interacting with the main component and removed from the condensate at the stage of its formation and/or subsequent heat treatment operations.

3. Active additives interacting with the main component through simple or complex multistep reactions, in particular those accompanied by formation and removal of gaseous products for the reaction zone.

Aluminium oxide is an example of additives of the first group, and sodium chloride - an example of the second group additives for condensates based on zirconium and aluminium oxides [30].

Reactive gas, for instance, oxygen, can be used as an additive from the third group, which is added to the vapour flow of evaporated $8 Y S Z$ to restore condensed layer $[8,27]$. For condensates based on zirconium dioxide, simple additives of the third group can also be many substances, the choice of which is determined by binary constitutional diagrams, for instance. For instance, addition of metallic zirconium (by simultaneous joint evaporation of 8YSZ ingot and zirconium ingot from two adjacent evaporators) to the vapour phase allows changing the phase composition and relief of condensation surface, as well as phase composition, structure and properties of individual crystallites of zirconium dioxide. Microstructures given in Figures 8 and $\mathbf{9}$ show the nature of variation of columnar crystallite structure in $\mathrm{ZrO}_{2}-$ $15 \mathrm{wt} . \% \mathrm{Y}_{2} \mathrm{O}_{3}(15 \mathrm{YSZ})$ layer deposited on a substrate heated up to $1000^{\circ} \mathrm{C}$, at simultaneous evaporation of $15 \mathrm{YSZ}$ and $\mathrm{Zr}$ ingots. Further addition of $7-8 \mathrm{wt} . \%$ of metallic zirconium to the vapour flow leads to transition from purely columnar microstructure of condensed layer to dendritic-columnar one. Crystallites of a pronounced dendritic form and two kinds of microporosity are formed, namely fine between the dendrite branches and more coarse in the interdendritic spaces.

At subsequent heat treatment in air free zirconium turns into zirconium dioxide as a result of oxidation. Such a microstructure is more stable to sintering at a high temperature. Figures $\mathbf{9 a}$ and $\mathbf{9 b}$ show the microstructure of the former coatings after static oxidation in air at $1200^{\circ} \mathrm{C}$ for 


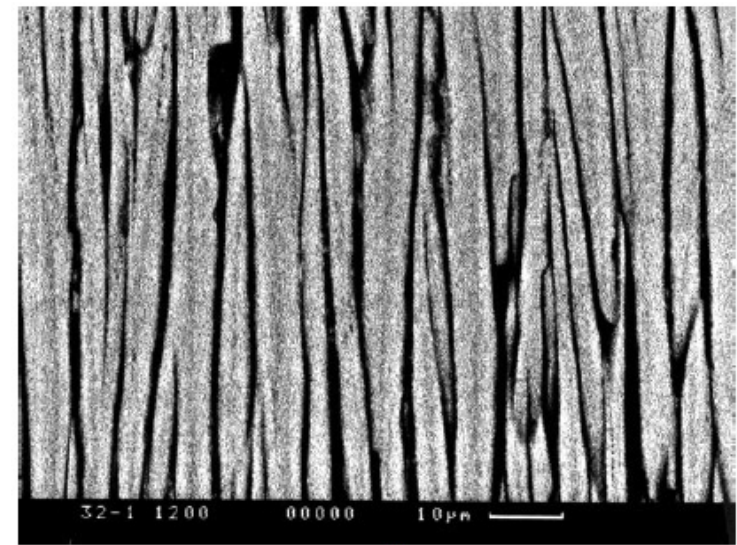

a)

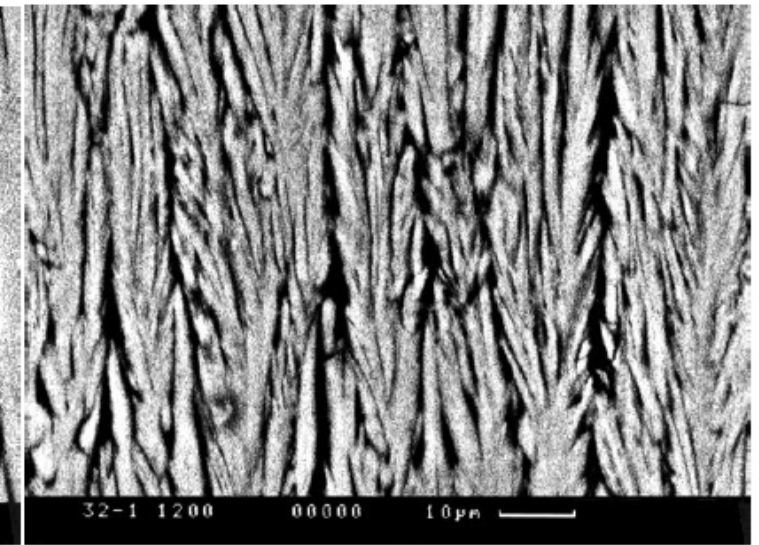

b)

Figure 8: Microstructure of as-deposited ceramic layer of $15 \mathrm{YSZ}(\mathbf{a})$ and $15 \mathrm{YSZ}+(7-8) \mathrm{wt} . \% \mathrm{Zr}$ (b).

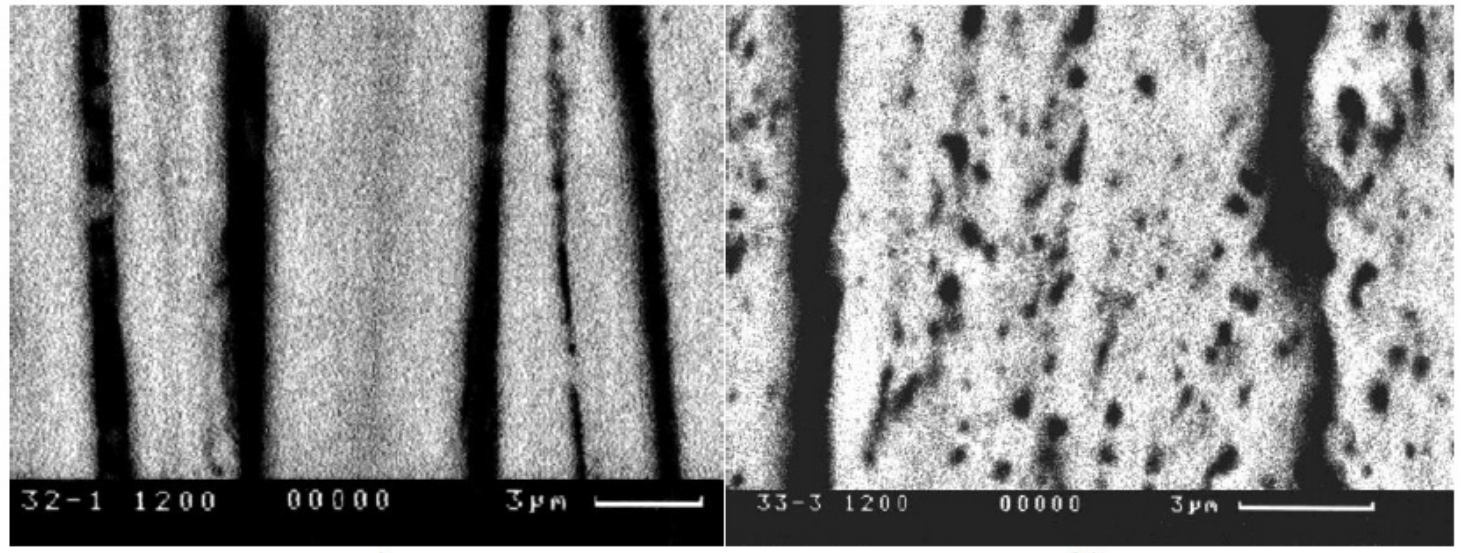

a) b)

Figure 9: Microstructure of ceramic layer of $15 \mathrm{YSZ}(\mathbf{a})$ and $15 \mathrm{YSZ}+(7-8) \mathrm{wt} \% \mathrm{Zr}(\mathbf{b})$ after annealing in air at $1200^{\circ} \mathrm{C}$ for $10 \mathrm{~h}$.

$10 \mathrm{~h}$. Columnar structures with gaps (micropores) $0.8-1.0$ $\mu \mathrm{m}$ wide between the crystallites remained practically unchanged, compared to structures in Figure 8a. Dendritic structure (Figure 8b) was changed after annealing. Partial sintering of inner volumes of the dendrites occurred with formation of spherical micropores, accompanied by a certain shrinkage (reduction of average width) of the crystallites. This resulted in a slightly greater average width of interdendritic spaces with simultaneous smoothing of the initial toothed relief of the side surface of the crystallites. Intensive sintering proceeded in the sections, where initial contacts occurred between the crystallites or in the interbranch spaces of individual dendrites.

\section{EXAMPLES OF HIGH-TEMPERATURE COATINGS AND THEIR PROPERTIES}

Use of composite ceramic ingot for deposition of multilayered thermal-barrier coatings of Me-Cr-Al-Y/YSZ type not only allows deposition of the entire coating in one process cycle, but also enables adding transition zones to coating structure, slowing down the diffusion processes and improving coating performance. Composition and thickness of coating metal layer (NiAl or NiCoCrAlY), including transition zones, is determined proceeding from the composition of superalloy of the blade, as well as specific service conditions and design of gas-turbine engines (GTE) blade. For instance, air-cooled GTE blades from modern thermally-stable superalloys of the last generations, as a rule, have small wall thickness of the airfoil and inner cavity (about $0.5 \mathrm{~mm}$ ) and small diameter cooling holes. For maximum lowering of weight and, accordingly, load on such blades and minimum narrowing of perforation holes, the coatings applied for their protection should have minimum thickness. In such cases, it is rational to use a coating variant with oxidation-resistant metal layer based on nickel aluminide, the thickness of which is not higher than 25-45 $\mu \mathrm{m}$, while in traditional thermal-barrier coatings the thickness of oxidation-resistant metal layer is 2-3 times higher.

For protection of less thermally-stable superalloys thermalbarrier coatings having a metal layer of increased thickness are used, in order to limit the diffusion flows in coating/superalloy composition. Such superalloys, as a rule, contain a higher level of titanium, tantalum, hafnium, sulphur and carbon. 
Specific variants of proposed coatings are given below.

Studied graded multilayer coatings were deposited on superalloy samples which were positioned in the fixture above composite ceramic ingot of $68.5 \mathrm{~mm}$ diameter placed in a copper water-cooled crucible. Samples were heated by electron beam up to the temperature of $950^{\circ} \mathrm{C}$ in vacuum, which was followed by electron beam heating of the surface of composite ceramic ingot with subsequent evaporation of inserts-fragments on its surface, and then of the entire ingot. After deposition on superalloys all the coatings are subjected to vacuum heat treatment at the temperature of $1080-1100^{\circ}$ $\mathrm{C}$ to form a thin film based on $\alpha-\mathrm{Al}_{2} \mathrm{O}_{3}$ on the metal/ceramic contact boundary, so-called TGO (thermally grown oxide).

As is known one of the main causes for fracture of thermalbarrier coatings in blade service, is subsequent growth of $\mathrm{Al}_{2} \mathrm{O}_{3}$-based film on the metal layer surface, which after achievement of a certain critical thickness, delaminates because of arising stresses, together with ceramic layer [32]. This is also promoted by diffusion of some refractory metals from superalloy towards the metal layer/ceramic layer interface. Therefore, one of the main goals in development of the first group of coatings, having a smaller thickness of $\mathrm{NiAl}$ layer, is slowing down of $\mathrm{Al}_{2} \mathrm{O}_{3}$ film growth and diffusion processes in superalloy/metal layer system.

Figure $\mathbf{1 0}$ gives the structure and composition of a composite ingot, used for deposition of a thermal-barrier graded $\mathrm{M}_{\mathrm{x}} \mathrm{C}_{\mathrm{y}}+\mathrm{NiAl} / 8 \mathrm{YSZ}$ coating (a), distribution of chemical elements (b) and microstructure (c) of this coating in the initial state (after deposition and heat treatment in vacuum). Coating was produced by evaporation of a composite 8YSZ ceramic ingot, having on its surface inserts of pre-sintered $\mathrm{NiAl}$ and anthracene $\mathrm{C}_{14} \mathrm{H}_{10}$ in the form of tablets (Figure 10a), with subsequent deposition directly on the surface of superalloy heated up to $950^{\circ} \mathrm{C}$. A distinctive feature of this graded coating, consisting of $\mathrm{NiAl}$ metal layer $20-25 \mu \mathrm{m}$ thick and outer ceramic layer $150 \mu \mathrm{m}$ thick, is presence of a thin transition zone, enriched in carbides of alloying elements of superalloy $\mathrm{M}_{\mathrm{x}} \mathrm{C}_{\mathrm{y}}$ (primarily tungsten and chromium carbides), which forms on the interface of superalloy - metal layer and creates a diffusion barrier, slowing down penetration of superalloy elements to ceramic layer.

Formation of this transition zone enriched in carbides, occurs due to initial evaporation of an insert of anthracene $\mathrm{C}_{14} \mathrm{H}_{10}$, embedded into ceramic ingot structure. Here also cleaning of superalloy surface takes place due to reducing action of hydrogen atoms, formed at hydrocarbon decomposition. As a result, a thermal barrier coating consisting of a graded metal layer and outer ceramic layer forms on superalloy surface in one vacuum cycle of deposition. At subsequent vacuum heat treatment $\mathrm{a}-\mathrm{Al}_{2} \mathrm{O}_{3}$ oxide film (TGO) forms on the surface of $\mathrm{NiAl}$ layer, containing up to $30 \%$ aluminium.

Figure 11a,b gives element distribution and microstructure of $\mathrm{M}_{\mathrm{x}} \mathrm{C}_{\mathrm{y}}+\mathrm{NiAl} / 8 \mathrm{YSZ}$ coating after 680 thermal cycles of testing in

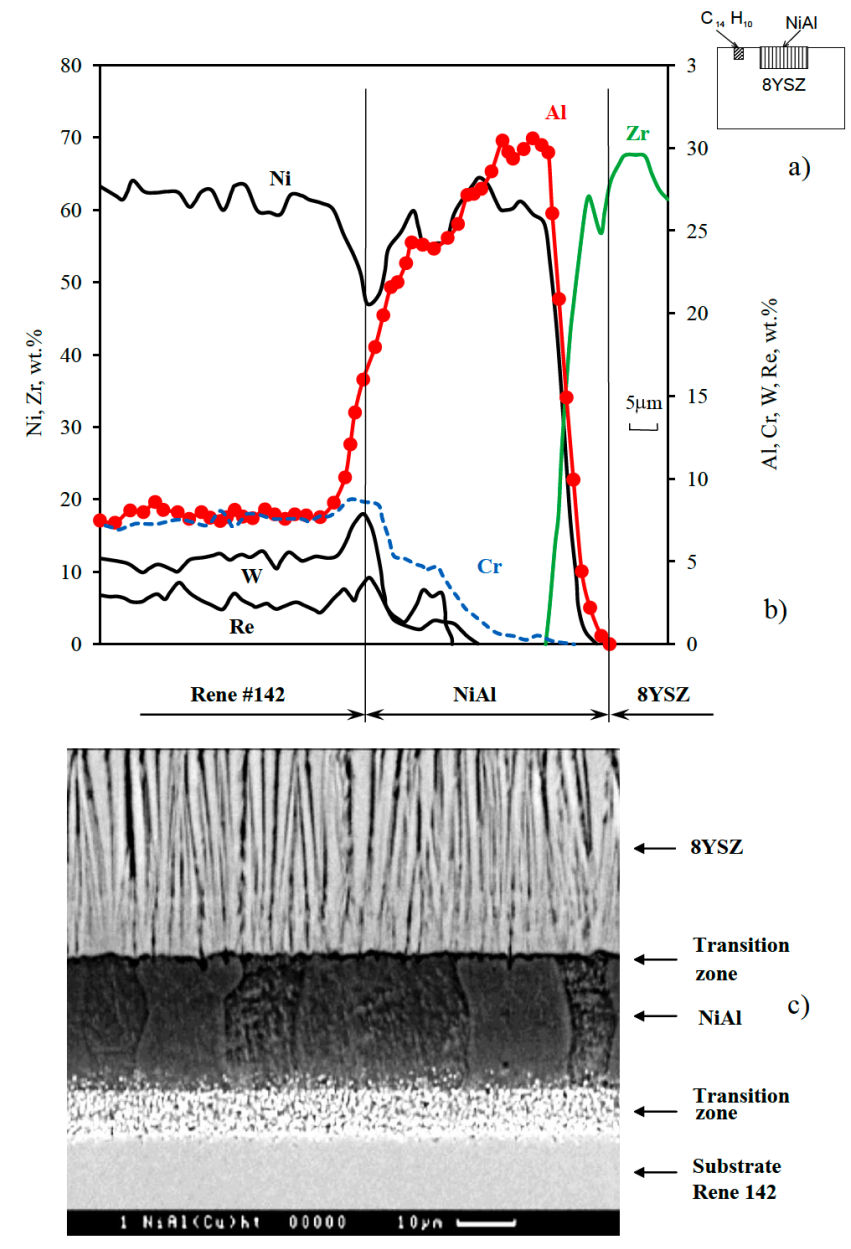

Figure 10: Structure of a composite ingot (a), chemical element distribution through coating thickness (b) and cross-sectional microstructure (c) of thermal-barrier graded $\mathrm{M}_{\mathrm{x}} \mathrm{C}_{\mathrm{y}}+\mathrm{NiAl} / 8 \mathrm{YSZ}$ coating on Rene-142 substrate in the initial condition.

the mode of $50^{\circ} \mathrm{C} \leftrightarrow 1093^{\circ} \mathrm{C}$ with soaking for $45 \mathrm{~min}$ at maximum temperature. Thickness of $\mathrm{Al}_{2} \mathrm{O}_{3}$ scale layer on $\mathrm{NiAl} / 8 \mathrm{YSZ}$ boundary is not higher than $8 \mu \mathrm{m}$, carbideenriched layer effectively slowed down diffusion of $W, R e$ and, to a smaller degree, Ti from the superalloy. There is no diffusion of these refractory elements from the superalloy into the 8YSZ layer.

The second group of thermal-barrier graded coatings includes graded coatings, deposited on the surface of traditional oxidation-resistant NiCoCrAIY metal layer (SDP-1 type). In this variant of graded coatings, the following steps are successively performed in the vacuum chamber of EBPVD unit in one technological cycle: a oxidation-resistant NiCoCrAIY layer is deposited (by evaporation of metal ingot of the required composition from a separate evaporator) and the fixture with the parts is immediately moved so that they are located above the next evaporator with the composite ingot, and after that its evaporation and deposition of a graded thermal barrier coating begin. As was already noted, application of a thicker NiCoCrAIY layer is preferable in the case of insufficiently thermally-stable superalloys. 


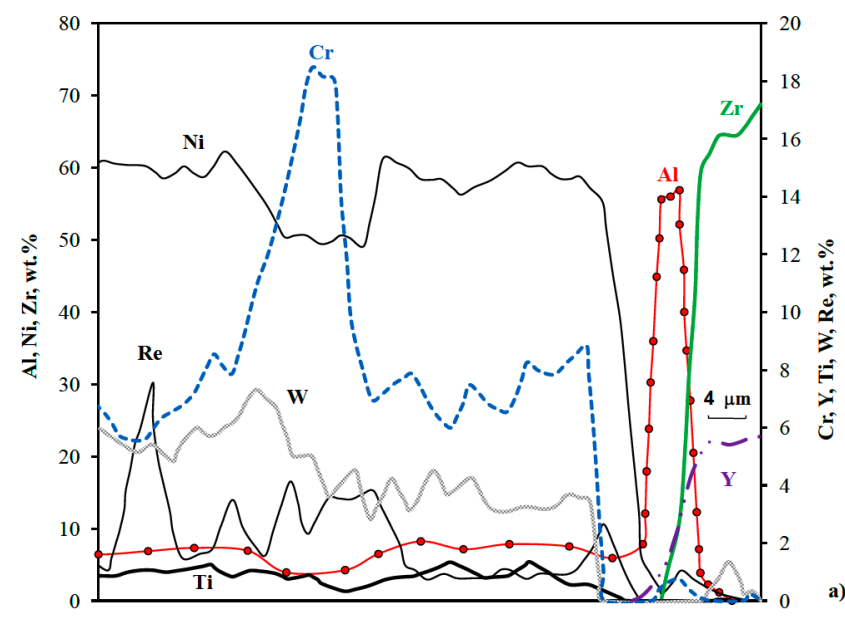

b)

Figure 11: Chemical element distribution through coating thickness (a) and cross-sectional microstructure (b) of thermal-barrier graded $\mathrm{M}_{\mathrm{x}} \mathrm{C}_{\mathrm{y}}+\mathrm{NiAl} / 8 \mathrm{YSZ}$ coating on $\mathrm{CMSX}-4$ substrate after 680 thermal cycles.

One of the variants of graded coating deposited on $\mathrm{NiCoCrAIY}$ layer is a coating containing $\mathrm{Al}+\mathrm{Cr}$ transition zone. Structure and composition of composite ingot (a), used for deposition of thermal-barrier graded NiCoCrAIY/ $\mathrm{Al}+\mathrm{Cr} / 8 \mathrm{YSZ}$ coating, distribution of chemical elements in this coating (b) and its microstructure (c) are given in Figure 12. Aluminium contained in the tablet (Figure 12a), has the highest vapour pressure at evaporation temperature, compared to $\mathrm{Cr}$ and $8 \mathrm{YSZ}$, so that it is the first to evaporate. Aluminium atoms collide with NiCoCrAIY surface heated to a temperature much higher than aluminium melting temperature $\left(660^{\circ} \mathrm{C}\right)$ and their condensation by vapour-liquidsolid phase mechanism takes place. Condensing liquid phase actively interacts with NiCoCrAIY layer surface, changing its chemistry, and forming a layer with a high content of aluminium close in its composition to NiAl. Then chromium is deposited from the tablet, forming on aluminide surface a thin, about $2-3 \mu \mathrm{m}$ film, transition zone with up to $40 \%$ chromium content, which directly contacts zirconium dioxide layer deposited after that, Figure 12b. Chromium and chromium oxide contained in the transition zone, favour formation of predominantly $\alpha-\mathrm{Al}_{2} \mathrm{O}_{3}$, creating an effective diffusion barrier and slowing down, first of all, growth of aluminium oxide layer, Figures $12 b$ and $13 a$. Results given in
Figure 13 of investigation of the composition of graded thermal barrier NiCoCrAIY/AI+Cr/8YSZ coating on a sample of superalloy CM-186 after thermal cycling tests show that the transition zone containing an increased content of aluminium and chromium on the contact boundary with $8 \mathrm{YSZ}$ layer, is an effective diffusion barrier, slowing down both the growth of TGO, the thickness of which reaches $12 \mu \mathrm{m}$, and penetration of refractory elements (in particular, tungsten) from the superalloy into 8YSZ ceramic layer. Tungsten content in NiCoCrAIY layer reaches $4 \%$, however, no diffusion of it into 8YSZ layer takes place.

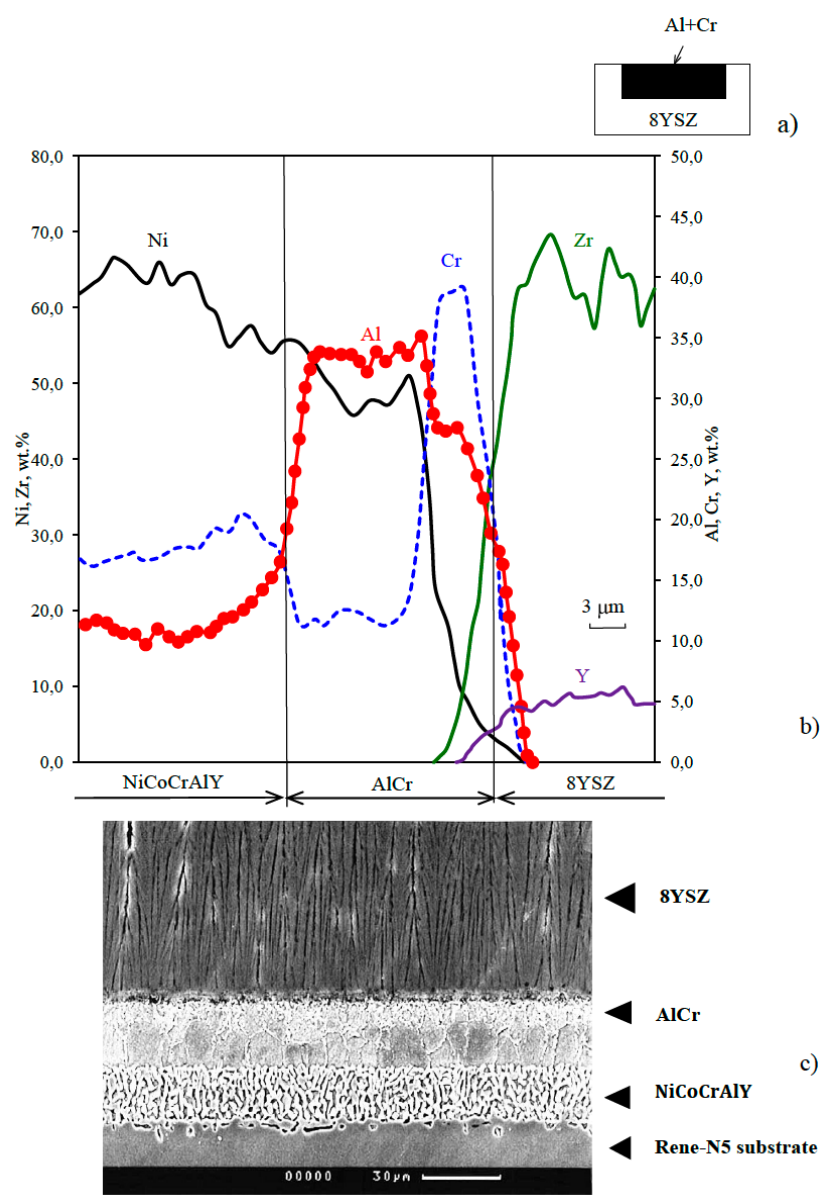

Figure 12: Structure of a composite ingot (a), chemical element distribution through coating thickness (b) and cross-sectional microstructure (c) of thermal-barrier graded NiCoCrAlY/Al+Cr/8YSZ coating on Rene- 5 substrate in the initial condition.

Coatings with NiCrCoAIY metal layer are effective for protection of high-temperature alloys of Rene 142, CM186LC, PWA 1480 type.

One of the examples of the possibility of creating graded structures of outer ceramic layer is the variant of composite ingot shown in Figure 14. In addition to earlier described inserts of anthracene $\mathrm{C}_{14} \mathrm{H}_{10}$ and NiAl placed on $8 \mathrm{YSZ}$ ingot surface, inserts from gadolinium oxide are placed in the ingot bottom part, Figure 14a. With the start of heating of such a composite ingot surface, successive evaporation of anthracene and nickel aluminide takes place, and then 
ceramic ingot evaporation starts. It evaporates completely, and at the final stage of evaporation the vapour flow also begins to be enriched in evaporating gadolinium oxide, the content of which in the coating surface zone increases with a gradient, Figures $14 \mathrm{~b}$ and $\mathbf{1 4 c}$, reaching $25-30 \%$ content. Graded layer thickness and gadolinium oxide concentration in it can be readily controlled by changing the mass and length of gadolinium oxide inserts.
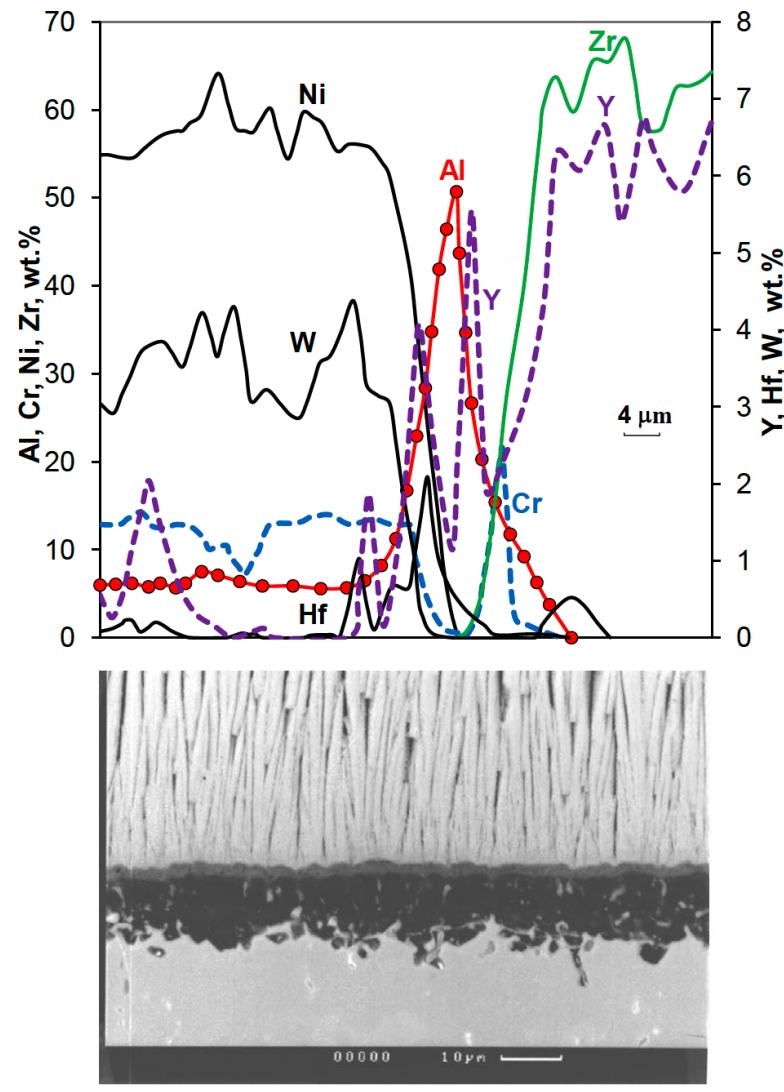

b)

Figure 13: Chemical element distribution through coating thickness (a) and cross-sectional microstructure (b) of thermal-barrier graded NiCoCrAIY/AI+Cr/8YSZ coating on CM-186 substrate after 1000 thermal cycles.

In addition to lowering thermal conductivity to the level of 1.1 $\mathrm{W} / \mathrm{m} \cdot \mathrm{K}$, Figure 7 , curve 3 , addition of gadolinium oxide ensures an increase of resistance to corrosion destruction by surface atmospheric salt precipitates, being in the liquid state at increased temperature, known as CMAS impact [33].

Results given in Figure 15 of studying the thermal cyclic life of various variants of coatings on different superalloys in furnace testing in air show that as regards cyclic life-time, graded thermal barrier coatings deposited by single-step technology by evaporation of the composite ceramic ingot exceed $1.7-1.8$ times the two-layer NiCoCrAIY/8YSZ coatings produced by the traditional multistage technology. This is attributable to their higher thermal stability and oxidation resistance, owing to formation of graded transition zones on the interface of metal layer/superalloy and on metal/ceramic interface, which delay the diffusion processes

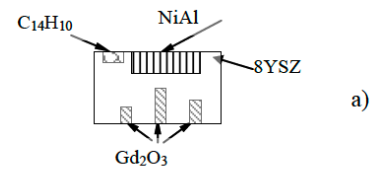

a)

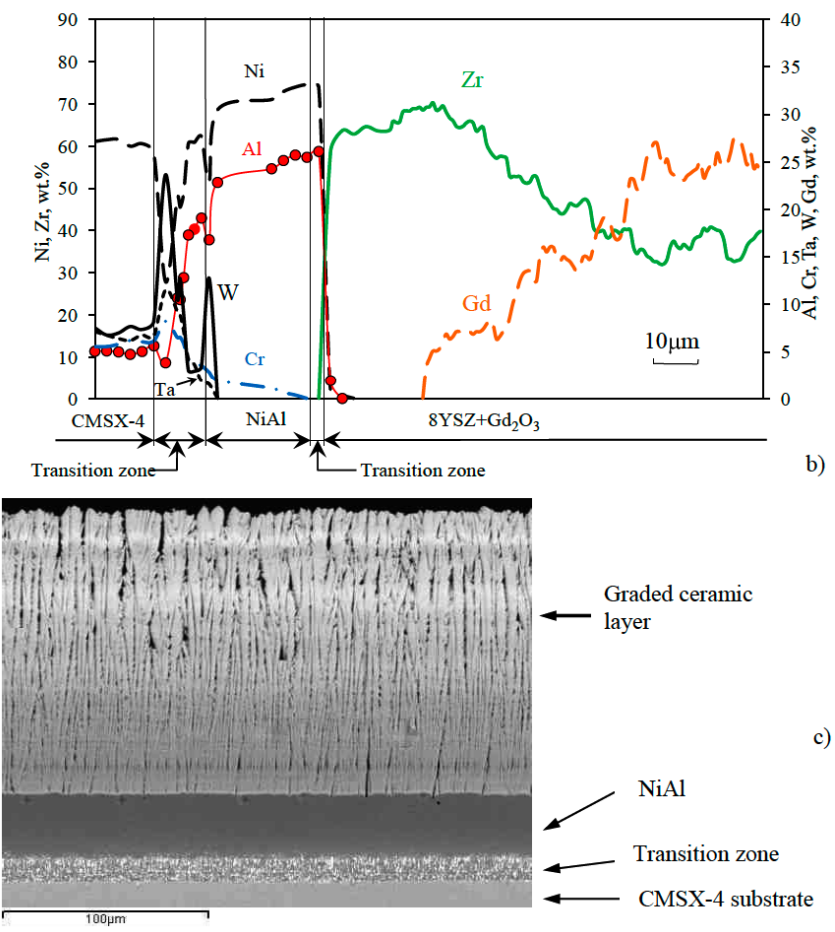

Figure 14: Structure of a composite ceramic ingot (a), distribution of chemical elements across coating thickness (b), and microstructure (c) of graded $\mathrm{M}_{\mathrm{x}} \mathrm{C}_{\mathrm{y}}+\mathrm{NiAl} / 8 \mathrm{YSZ}+\left(8 \mathrm{YSZ}+\mathrm{Gd}_{2} \mathrm{O}_{3}\right)$ TBC after vacuum heat treatment at $1100^{\circ} \mathrm{C}$ for $1 \mathrm{~h}$.

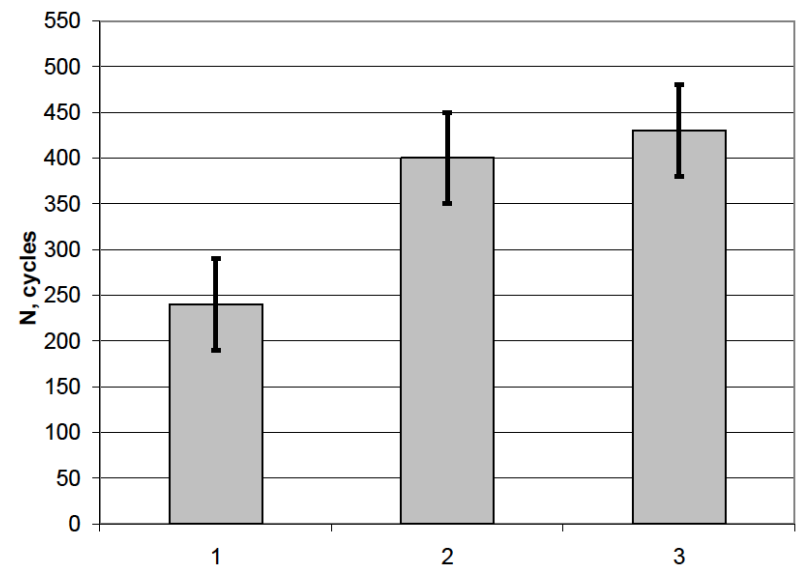

Figure 15: Thermal cyclic life-time of samples with thermal-barrier coatings at furnace testing in air $\left(50 \leftrightarrow 1150^{\circ} \mathrm{C}\right)$, depending on oxidation-resistant metal layer type.

1 - traditional thermal-barrier NiCoCrAlY/8YSZ coatings on samples of superalloys Rene N5, Rene 142, CMSX-4;

2 - graded thermal-barrier $\mathrm{M}_{\mathrm{x}} \mathrm{C}_{\mathrm{y}} / \mathrm{NiAl} / 8 \mathrm{YSZ}$ coatings on samples of superalloys Rene N5, Rene 142, CMSX-4;

3 - graded thermal-barrier $\mathrm{NiCoCrAIY}(\mathrm{Al}+\mathrm{Cr}) / 8 \mathrm{YSZ}$ coatings on samples of superalloys Rene N5, Rene 142, CM186LC.

on these interfaces. This is further confirmed by the results given in Table 1 which demonstrate slowing down of growth 
Table 1: Results of measurement of thickness of $\mathrm{Al}_{2} \mathrm{O}_{3}$-based film, forming in metal layer / ceramic layer transition zone at thermal cycling tests in the mode of $50 \leftrightarrow 1150^{\circ} \mathrm{C}$ on samples of superalloy of Rene 142 type

\begin{tabular}{|c|c|c|c|c|}
\hline \multirow[t]{2}{*}{ Thermal barrier coating } & \multicolumn{4}{|c|}{ Thickness of $\mathrm{Al}_{2} \mathrm{O}_{3}$-based film, $\mu \mathrm{m}$, depending on the number of thermal cycles } \\
\hline & 60 cycles & 250 cycles & 500 cycles & 600 cycles \\
\hline $\begin{array}{c}\text { Traditional } \\
\text { NiCoCrAIY/8YSZ }\end{array}$ & 5 & 10 & - & - \\
\hline $\begin{array}{c}\text { Graded } \\
\mathrm{M}_{\mathrm{x}} \mathrm{C}_{\mathrm{y}}+\mathrm{NiAl} / 8 \mathrm{YSZ}\end{array}$ & 2 & 6 & 7 & 8 \\
\hline $\begin{array}{c}\text { Graded } \\
\text { NiCoCrAlY/Al+Cr/8YSZ }\end{array}$ & 4 & 7 & 10 & - \\
\hline
\end{tabular}

kinetics of $\mathrm{Al}_{2} \mathrm{O}_{3}$ based film, which grows during thermal cycling tests on the interface between the metal layer and 8YSZ layer.

\section{EXAMPLES OF EQUIPMENT}

In the USSR development of EB-PVD technologies and equipment for deposition of high-temperature coatings was concentrated at the E.O.Paton Electric Welding Institute (Kiev, Ukraine). In 1980-1991 fifteen specialized industrial units of UE-175, and UE-187 type for coating deposition on gas turbine blades operated at the enterprises of USSR (aviation and shipbuilding industries, Gasprom) [18]. These, as well as new generation units of UE-204, UE-207, UE-208 type, have 4 to 6 flat-beam guns [6] of $60 \mathrm{~kW}$ power each with $18-20 \mathrm{kV}$ accelerating voltage for evaporation and direct heating of parts (blades) and one high-voltage power source for all the guns.

Selection of a relatively low level of accelerating voltage (20 $\mathrm{kV}$ ) was dictated by the need to:

provide the possibility of evaporation of compounds, primarily oxides, at the specified rate at minimum degree of their dissociation (decomposition) under the impact of electron flow;

application of "soft" direct electron beam heating of the substrate, preventing the possibility of damage (surface melting) of substrate surface microvolumes; lowering of the weight and cost of electron beam equipment due to reducing the thickness of vacuum chamber walls, required for "biological " protection of $\mathrm{X}$-ray radiation.

Development of electron beam units in Europe and USA followed the path of construction of large-sized highly specialized high-efficient installations for coating deposition mainly on gas turbine blades [34,35]. Special features of these installations are application of axial electron beam guns of up to $100-250 \mathrm{~kW}$ power with up to $40 \mathrm{kV}$ accelerating voltage, as well as predominant application of radiation heating of parts.

International Center for Electron Beam Technologies (IC EBT) of the E.O.Paton Electric Welding Institute, which began its activities in 1994, developed and is currently producing three types of new units of the second generation, Figure 16:

- $\quad$ laboratory units UE-205, UE-209, UE-210;

- $\quad$ pilot-production units UE-204;

- $\quad$ production units UE-207X, UE-207S.

All the units differ by the number and power of evaporators, dimensions of working and loading chambers, gun chambers, etc., but enable performance of all the known technological variants of electron beam evaporation and subsequent deposition of vapour phase on a substrate of specified configuration, in particular of high-temperature coatings.

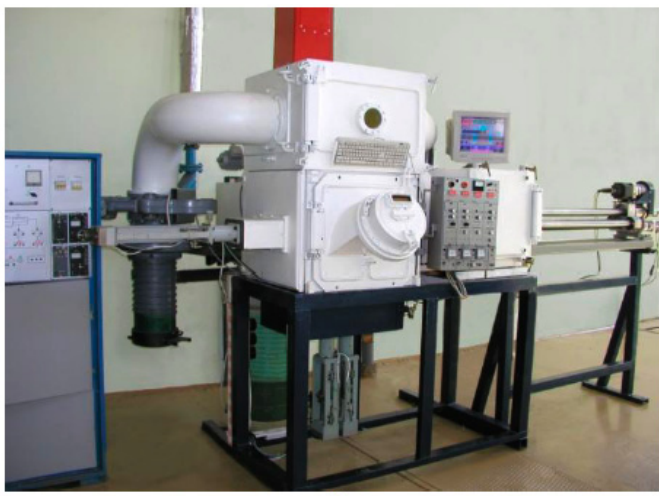

a)

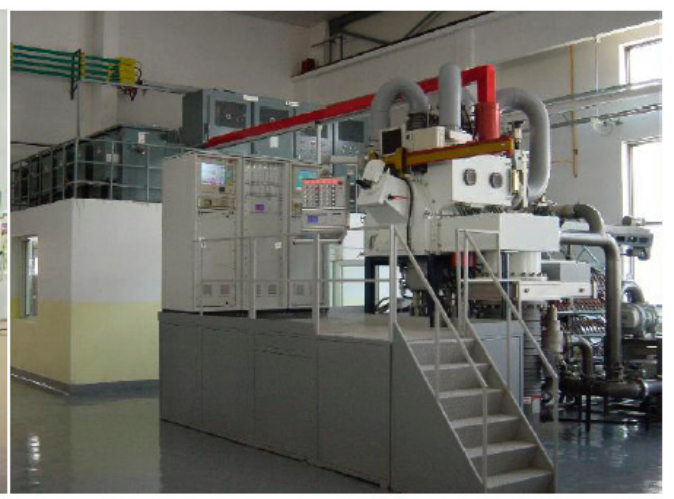

b)

Figure 16: Electron beam units of laboratory type UE-209 (a) and pilot-production type UE-204 (b). 


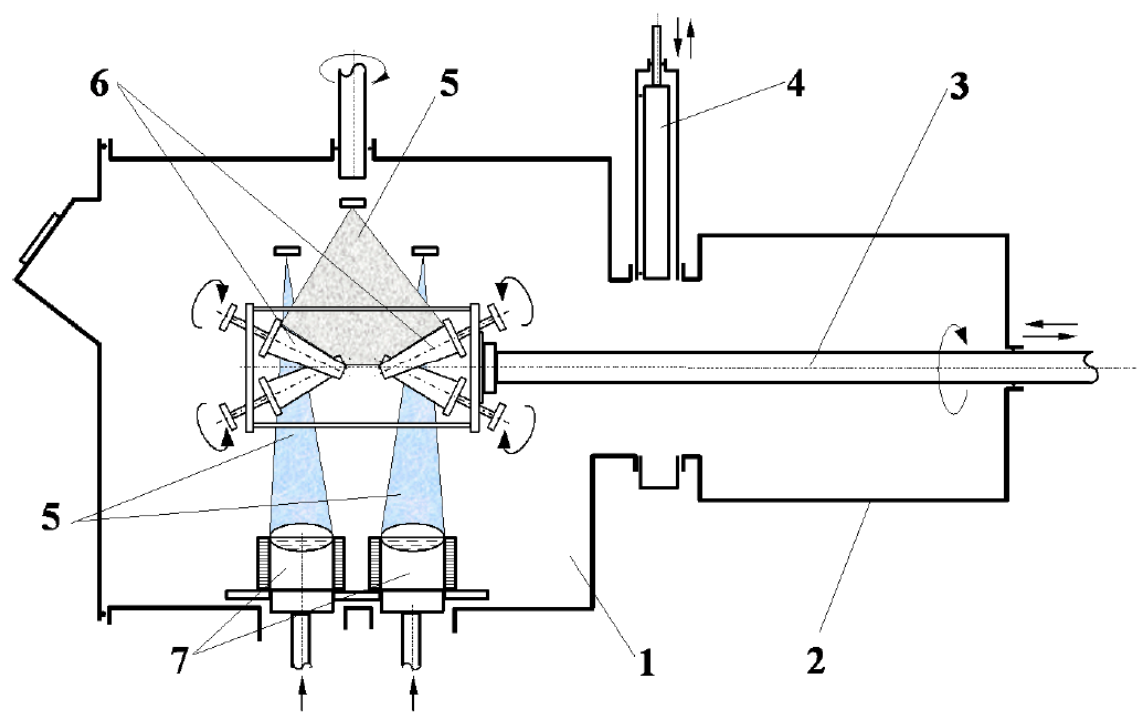

Figure 17: Technological sequence of electron beam deposition of coatings on gas turbine blades.

1 - main chamber; 2 - loading chamber; 3 - horizontal shaft; 4 - vacuum gate valve; 5 - electron beam for heating and evaporation; 6 - blades; 7 - evaporation ingots.

Figure 17 shows an example of technological sequence of protective coating deposition on gas turbine blades in the unit of UE-207S type.

One of the features of electron beam units of UE-type is also the possibility of mounting carousel-type multicrucible evaporators for evaporation of composite ceramic ingots at single-stage process of graded coating deposition.

Figure 18 shows the general view of an evaporator block consisting of traditional evaporator, and 5-position carouseltype evaporator. Such an evaporator block is designed, primarily, for deposition of graded thermal-barrier coatings by single-stage technology by evaporation of composite ceramic ingots from carousel-type multicrucible evaporator. In the case of the need to deposit oxidation-resistant metal layer of MCrAIY type a metal ingot of the respective chemical composition is used, placed into the traditional evaporator. Deposition of transition zones and outer ceramic layer of thermal-barrier coating is performed by heating and subsequent complete evaporation of one composite ceramic ingot. Carousel rotation by a fixed angle ensures displacement of the next composite ceramic ingot for coating the next batch of parts (blades).

Appearance of various-purpose blades of gas-turbine engines, with high-temperature coatings deposited on them by EB-PVD method, is shown in Figure 19.

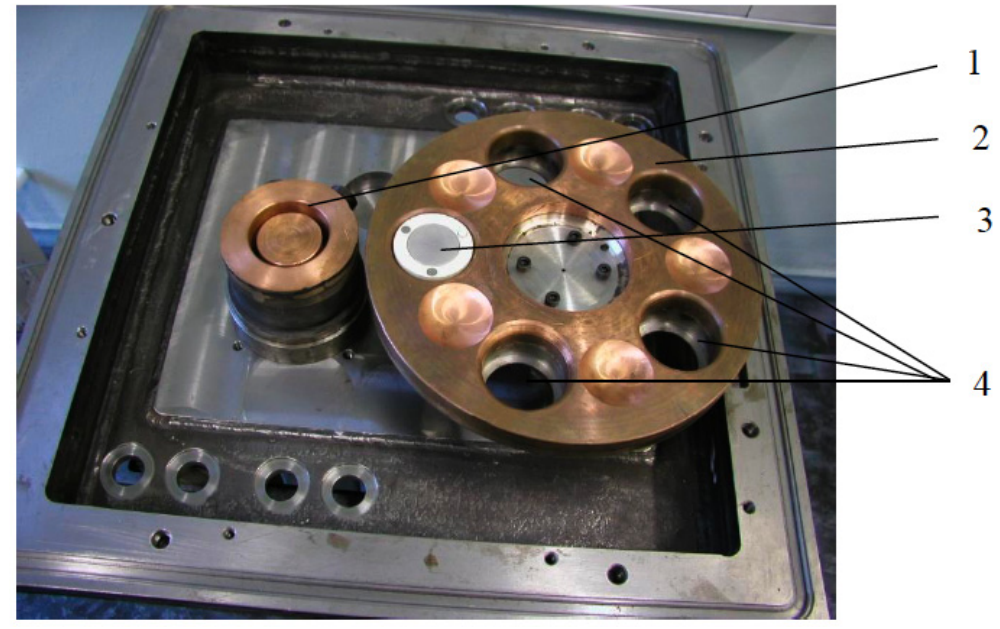

Figure 18: General top view of an evaporators block with carousel type-evaporator:

1 - traditional water-cooled crucible of $70 \mathrm{~mm}$ diameter;

2 - carousel-type evaporator with 5 positions of $70 \mathrm{~mm}$ diameter for composite ingots;

3 - composite ceramic ingot;

4 - positions for composite ceramic ingots. 


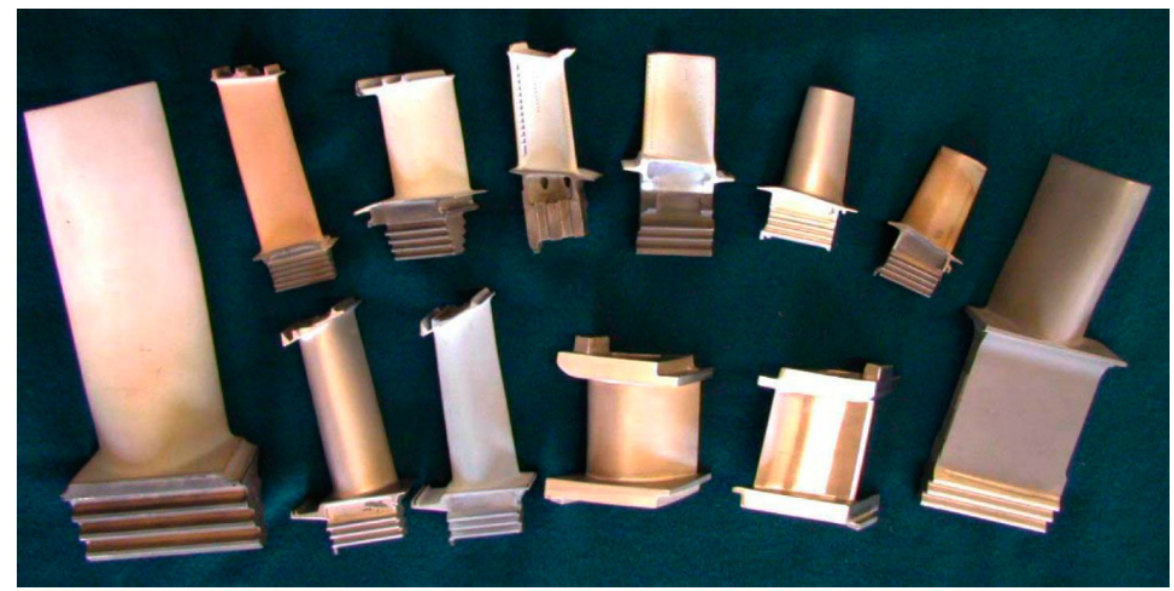

Figure 19: Examples of gas turbine blades with high-temperature coatings deposited by EB-PVD.

\section{CONCLUSIONS}

1. EB-PVD method allows "designing" high-temperature multilayered protective coatings of metal/ceramic type.

2. Me-Cr-Al-Y/YSZ bilayer coatings deposited successively from two independent sources on the surface of various-purpose gas turbine blades have already become widely applied in practice.

3. Special attention should be given to technological variant of single-stage process of multilayered coating deposition by evaporation of a composite ingot from one source.

\section{ACKNOWLEDGEMENT}

Authors express special appreciation and gratitude to Dr. Uwe Schulz (DRL, Germany) for providing the initial substrate samples and heat conductivity studies (Figure 7).

\section{REFERENCES}

[1] Bunshah RF. Vacuum evaporation - history, recent developments and applications. Z metallkunde 1984; 75(11): 840-846

[2] Bunshah RF. Handbook of deposition technologies for films and coatings: science, technology and applications. $2^{\text {nd }}$ ed. Park Ridge, N.J.: Noyes Publications 1994.

[3] Movchan BA, Yakovchuk KYu. Graded thermal barrier coatings, deposited by EB-PVD. Surface and Coatings Technology 2004; 188189: 85-92.

http://dx.doi.org/10.1016/..surfcoat.2004.08.006

[4] Movchan BA, Malashenko IS. Zharostoykiye pokritiya osazhdayemiye $\checkmark$ vacuume. Kiev: Naukova dumka 1983.

[5] Movchan BA. Inorganic materials and coatings produced by EB-PVD. Surface Engineering 2006; 22(1): 35-46. http://dx.doi.org/10.1179/174329406X85029

[6] Movchan BA, Gavriljuk OJ. Electron beam projector provided with a linear thermionic emitting cathode for electron beam heating. United States Patent US 7,042,145. 2006 May.

[7] Tamarin Y. Protective coatings for turbine blades. Ohio: ASM. Intern 2002.

[8] Levi CG. Emerging materials and processe for thermal barrier systems. Solid State and Materials Science 2004; 38: 77-91.

[9] Clarke DR, Oechsner M, Padture N. Thermal barrier coatings for more efficient gas-turbine engines. MRS Bulletin Oct 2012; 37(10): 891-898.

http://dx.doi.org/10.1557/mrs.2012.232
[10] Evans AG, Mumm DR, Hutchinson JW, Meier GH, Petit FS Mechanisms controlling the durability of thermal barrier coatings. Progress in Materials Science 2001; 46: 505-553. http://dx.doi.org/10.1016/S0079-6425(00)00020-7

[11] ovchan BA, Malashenko IS, Yakovchuk KYu, Rybnikov Al, Tchizhik AA. Two- and three-layer coatings produced by deposition in vacuum for gas turbine blade application. Surface and Coatings Technology 1994; 67: 55-63.

http://dx.doi.org/10.1016/S0257-8972(05)80027-1

[12] Schulz U, Fritscher K, Peters M. Thermocyclic behavior of variously stabilized EB-PVD thermal barrier coatings. J Eng Gas Turbines Power 1997; 119(4): 917-921. http://dx.doi.org/10.1115/1.2817074

[13] Schulz U, Fritscher K, Leyens C. Two-source jumping beam evaporation for advanced EB-PVD TBC systems // Surface and Coatings Technology 2000; 133-134: 40-48. http://dx.doi.org/10.1016/S0257-8972(00)00871-9

[14] Yu Z, Dharmasena KP, Hass DD, Wadley HNG. Vapor deposition of platinum alloyed nickel aluminide coatings. Surface and Coatings Technology 2006; 201: 2326-2334.

http://dx.doi.org/10.1016/i.surfcoat.2006.04.020

[15] Mazurkiewicz A, Smolik J, Zbrowski A, Kacprzyńska J. Innovative technical solutions for evaporation of multilayer coatings by EB-PVD method. The Archives of Civil and Mechanical Engineering 2014; 14(2): 250-254.

http://dx.doi.org/10.1016/j.acme.2013.09.008

[16] Movchan BA, Korzh AV, Topal VI. United Technology Corporation (USA) and International Center for Electron Beam Technologies of E.O.Paton Electric Welding Institute (Ukraine). Method of vacuum vaporization of metals. European patent EP 0969115 (A1). 1997 May.

[17] Movchan BA, Nerodenko LM, Rudoy JE. International Center for Electron Beam Technologies of E.O.Paton Electric Welding Institute (Ukraine). Method for producing by evaporation a functionally graded coatings with an outer ceramic layer on a metal substrate. United States Patent US 6,669,982. 2003 Dec.

[18] Movchan BA, Yakovchuk KYu. Electron beam installations for evaporation and deposition of inorganic materials and coatings. Advances in Electrometallurgy 2004; 2: 9-14.

[19] Yakovchuk KYu, Rudoy YuE. Single-stage electron beam technology of deposition of thermal barrier gradient coatings. Advances in Electrometallurgy 2003; 2: 9-14

[20] Ratzer-Scheibe H-J, Schulz U, Krell T. The effect of coating thickness on the thermal conductivity of EB-PVD PYSZ thermal barrier coatings. Surface and Coatings Technology 2006; 200: 5636-5644. http://dx.doi.org/10.1016/j.surfcoat.2005.07.109

[21] Movchan BA, Demchishin AV. Investigation of the structure and properties of thick vacuum condensates of nickel, titanium, tungsten, aluminuim oxide and zirconium dioxide. Fiz Met Metalloved 1969; 28(4): 653-660.

[22] Thornton JA. Influence of apparatus geometry and deposition conditions on the structure and topography of thick sputtered coatings. J Vac Sci Technol 1974; 11: 666.

http://dx.doi.org/10.1116/1.1312732

[23] Sanpath S, Schulz U, Jarligo MO, Kuroda S. Processing science of advanced thermal barrier systems. MRS Bulletin October 2012 37(10): 903-910. 
[24] Thornton JA. High rate thick film growth. Annual Review of Materials Science 1977; 7: 239-260. http://dx.doi.org/10.1146/annurev.ms.07.080177.001323

[25] Schulz U, Terry SG, Levi CG. Microstructure and textureof EB-PVD TBCs grown under different rotation modes. Materials Science and Engineering 2003; 360: 318-328.

[26] Wada $K$, Yoshiya $M$, Yamaguchi $N$, Matsubara $H$. Texture and microstructure of $\mathrm{ZrO}_{2}-4$ mol. $\% \mathrm{Y}_{2} \mathrm{O}_{3}$ layers obliquely deposited by EB-PVD. Surface and Coatings Technology 2006; 200: 2725-2730. http://dx.doi.org/10.1016/j.surfcoat.2005.02.121

[27] Schulz U, Sarahan B, Fritscher K, Leyens C. Review on advanced EB-PVD ceramic topcoats for TBC applications. Int. Journal of Applied Ceramic Technology 2004; 1(4): 302-315. http://dx.doi.org/10.1111/j.1744-7402.2004.tb00182.x

[28] Hass DD, Slifka AJ, Wadley HNG. Low thermal conductivity vapor deposited zirconia microstructures. Acta Materialia 2001; 49: 973-983. http://dx.doi.org/10.1016/S1359-6454(00)00403-1

[29] Gu S, Lu TG, Hass TD, Wadley HNG. Thermal conductivity of zirconia coatings with zig-zag pore microstructures. Acta Mater 2001; 49: 2539-2547.

http://dx.doi.org/10.1016/S1359-6454(01)00141-0
[30] Movchan BA, Lemkey FD. Some approaches to producing microporous materials and coatings by EB PVD. Surface and Coatings Technology 2003; 165: 90.

http://dx.doi.org/10.1016/S0257-8972(02)00723-5

[31] Nicholls JR, Lawson KJ, Johnstone A, Rickerby DS. Methods to reduce the thermal conductivity of EB-PVD TBCs. Surface and Coatings Technology 2002; 151-152: 383-391. http://dx.doi.org/10.1016/S0257-8972(01)01651-6

[32] Evans AG, Mumm DR, Hutchinson GH, Meier GH, Pettit FS Mechanisms comtrolling the durability of thermal barrier coatings. Progress in Material Science 2001; 46: 505-553. http://dx.doi.org/10.1016/S0079-6425(00)00020-7

[33] Levi CG, Hutchinson JW, Vidal-Setif MH, Johnson CA. Environmenta degradation of thermal barrier coatings by molten deposits. MRS Bulletin 2012; 37(10): 931-941. http://dx.doi.org/10.1557/mrs.2012.230

[34] Turbine blade coatings - EB-PVD production systems. ALD Vacuum Technologies GmbH, Germany; Available from: http://web.aldvt.de/cms/fileadmin/pdf/prospekte/SMARTCoater_101012.pdf

[35] Reinhold E, Botzler P, Deus C. EB-PVD process management for highly productive zirconia thermal barrier coating of turbine blades. Surface and Coating Technology 1999; 120-121: 77-83. http://dx.doi.org/10.1016/S0257-8972(99)00344-8

(C) 2014 Movchan and Yakovchuk; Licensee Lifescience Global.

This is an open access article licensed under the terms of the Creative Commons Attribution Non-Commercial License (http://creativecommons.org/licenses/by-nc/3.0/) which permits unrestricted, non-commercial use, distribution and reproduction in any medium, provided the work is properly cited. 